\title{
Gel immersion endoscopic submucosal dissection for an anorectal tumor with hemorrhoids close to the dentate line
}
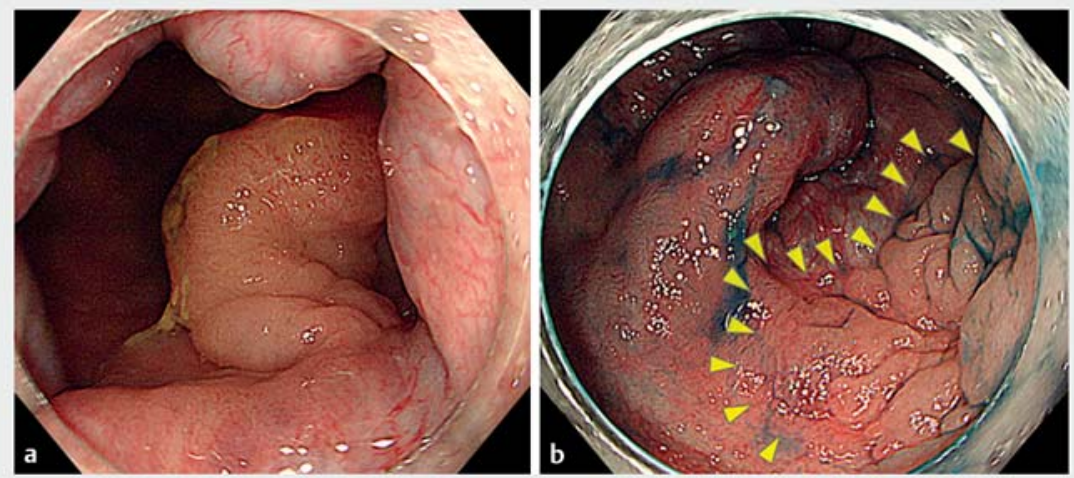

- Fig. 1 Endoscopy revealed a 40-mm protruded tumor in the anterior wall of the anorectum with hemorrhoids close to the dentate line. a Endoscopic image in forward view. b Endoscopic image in the retroflexed view. Demarcation line of the tumor (yellow arrows) close to the hemorrhoids.

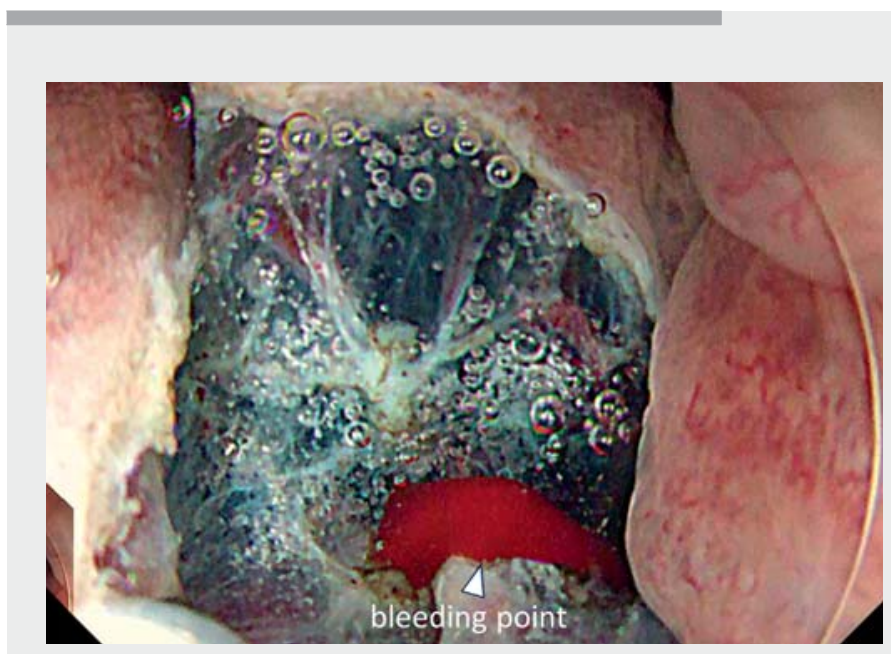

Video 1 Successful gel immersion endoscopic submucosal dissection for an anorectal tumor with hemorrhoids close to the dentate line.

Endoscopic submucosal dissection (ESD) of anorectal tumors close to the dentate line poses an increased risk of intraoperative and delayed bleeding due to the development of venous flora, including hemorrhoids, in the rectal submucosa. Moreover, the narrow lumen and proximity of the anal sphincter decrease maneuverability and visibility in the resection field $[1,2]$. Recently, during endoscopic hemostasis for gastrointestinal bleeding, the "gel immersion endoscopy" technique, involving injection of clear gel, was used to displace blood and clots to secure good visualization $[3,4]$. We report the use of a novel gel product (VISCOCLEAR; Otsuka Pharmaceuticals Factory, Chiyoda, Japan), with a short procedure time, to overcome the difficulty of ESD for anorectal tumors close to

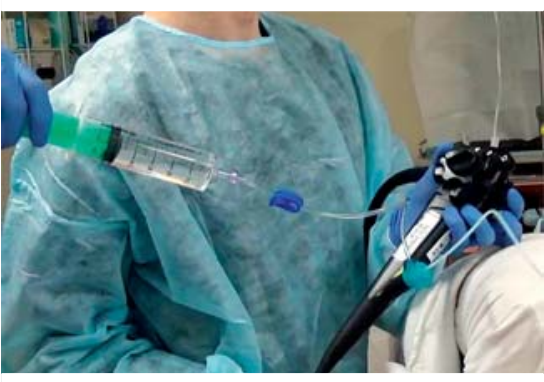

- Fig. 2 An endoscope (GIF-H290T; Olympus, Medical Systems Co., Tokyo, Japan) with the BioShield irrigator (US Endoscopy, Mentor, Ohio, USA). During endoscopic submucosal dissection, gel was injected and an electrosurgical knife (Flush Knife; Fujifilm Co., Tokyo, Japan) was used simultaneously through the accessory channel.

the dentate line; this has not been described previously.

A 78-year-old woman presented with an anorectal tumor with hemorrhoids close to the dentate line ( $\triangleright$ Fig. 1). ESD was required for en bloc resection of the tumor, but as hemorrhoids were scattered on the anal side of the tumor, hemorrhage during ESD was a concern. After obtaining written informed consent from the patient, gel immersion ESD was attempted ( $\triangleright$ Fig. 2, $\vee$ Video 1 ).

With gel immersion, particularly on the proximal side of the tumor, where the lumen is narrowed by the anal sphincter, the tumor's buoyancy provided a good dissection field (\$ Fig.3). Furthermore, as there was no carbon dioxide insufflation, the endoscope was not extruded from the patient's body during excretion of excessive insufflation gas stored in the colorectum. Thus, endoscopic maneuverability remained stable during resection on the proximal side. When unexpected massive bleeding occurred, additional gel injection enabled immediate and easy implementation of hemostatic procedures ( $\triangleright$ Fig.4). The tumor was resected en bloc within an operative time of 35 minutes (> Fig.5). 


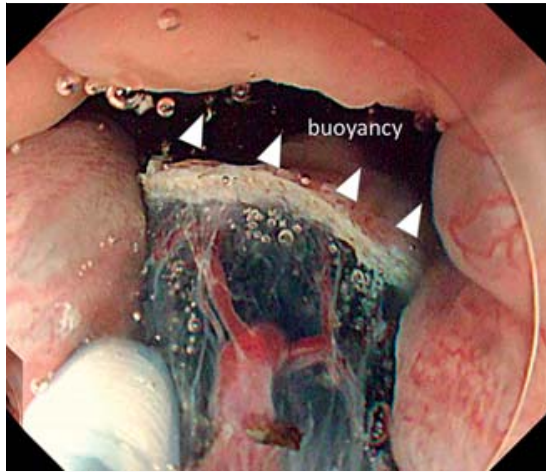

- Fig. 3 Endoscopic image of the proximal side of the tumor during gel immersion endoscopic submucosal dissection. After partial submucosal dissection, the buoyancy effect of the tumor (white arrows) provided a good dissection field.

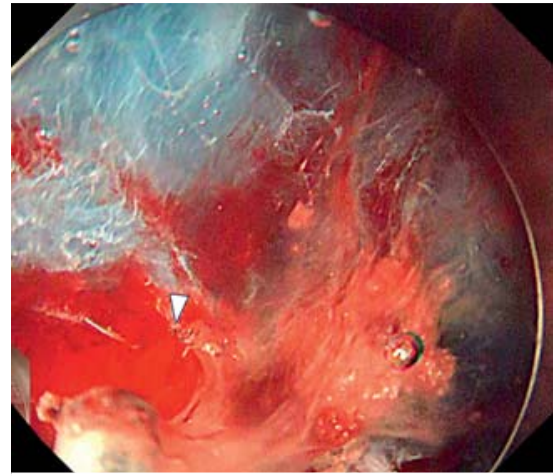

- Fig. 4 Intraoperative massive bleeding. After continuous injection of gel, the bleeding site could be identified accurately (white arrow).

[2] Probst A, Ebigbo A, Märkl B et al. Endoscopic submucosal dissection for rectal neoplasia extending to the dentate line: European experience. Endosc Int Open 2018; 6: E1355E1362

[3] Yano T, Nemoto D, Ono K et al. Gel immersion endoscopy: a novel method to secure the visual field during endoscopy in bleeding patients (with videos). Gastrointest Endosc 2016; 83: 809-811

[4] Miura Y, Yano T, Takezawa T et al. Gel immersion endoscopy simplifies hemostasis during endoscopic submucosal dissection using the pocket-creation method. Endoscopy 2018; 50: E294-E295

Bibliography

Endoscopy 2022; 54: E298-E299

DOI 10.1055/a-1519-6939

ISSN 0013-726X

published online 2.7.2021

(c) 2021. Thieme. All rights reserved.

Georg Thieme Verlag KG, Rüdigerstraße 14,

70469 Stuttgart, Germany

\section{ENDOSCOPY E-VIDEOS}

https://eref.thieme.de/e-videos

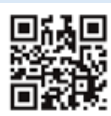

Endoscopy E-Videos is an open access online section, reporting on interesting cases and new techniques in gastroenterological endoscopy. All papers include a high quality video and all contributions are freely accessible online. Processing charges apply (currently EUR 375), discounts and wavers acc. to HINARI are available.

This section has its own submission website at

https://mc.manuscriptcentral.com/e-videos

Endoscopy_UCTN_Code_CPL_1AJ_2AD

\section{Competing interests}

The authors declare that they have no conflict of interest.

The authors

Tomoaki Tashima' ${ }^{\circledR}$, Yuya Nakano' ${ }^{1}$, Ryuhei Jinushi ${ }^{1}$, Kazuya Miyaguchi ${ }^{1}$, Rie Terada ${ }^{1}$, Tomonori Kawasaki ${ }^{2}$, Shomei Ryozawa ${ }^{1}$

1 Department of Gastroenterology, Saitama Medical University International Medical Center, Saitama, Japan
2 Department of Pathology, Saitama Medical University International Medical Center, Saitama, Japan

\section{Corresponding author}

\section{Tomoaki Tashima, MD, PhD}

Department of Gastroenterology, Saitama Medical University International Medical Center, 1397-1 Yamane, Hidaka City,

Saitama 350-1298, Japan

t.tashima1981@gmail.com

\section{References}

[1] Tamaru Y, Oka S, Tanaka S et al. Endoscopic submucosal dissection for anorectal tumor with hemorrhoids close to the dentate line: a multicenter study of Hiroshima GI Endoscopy Study Group. Surg Endosc 2016; 30: 4425-4431 